\section{Missing to Meet Dieticians and Nutritionists' Educational Needs is Not Only a Question of Governmental Austerity Measures}

Received: January 30, 2017; Accepted: February 04, 2017; Published: February 13, 2017

Most B.Sc. candidates in Nutrition and Dietetics recognise the necessity of anticipating the future and to learn new methodologies such as nutrigenomics. To own robust skill is a validated tool to survive scientifically throughout one's career. Motivated students even see new challenges as an opportunity for emerging added values for patients, for the society in general, and for the own profession. The article by Sadeghi et al. in this issue ("Continuing Educational needs and preferences for Swiss Registered Dietitians: Lessons learned" [1] examines in a SWOTlike analysis the educational need of dietitians as well as their preferences.

Teaching is not only providing established science but is more and more translating new knowledge issued from most recent research into basic undergraduate education, into post-graduate specialisation, as well as into life-long learning (continuing education) and common training frameworks. The willingness of teachers and researchers to respond to this educational need however stagnates due to restricted attribution of timeslots and due to overloaded schedules.

Planning and accreditation of a curriculum or of a post-graduate specialisation is a procedure which lasts currently at least 3-5 years. Meanwhile, research goes on. Basic education lags generally behind the scientific state of the art. Thus, with basic education alone the adequate translation from research into education will not be successful. Continuing education seems to be more open for a synchronisation of research portfolios and educational needs. However, private providers of life-long learning programs neither provide courses to satisfy educational needs nor do they translate recent research, unless a positive financial outcome is likely to result. As a result, many providers do normally not have long-term professional perspectives of more than only a few years. Long-term needs enabling to cope with circumstances arising in 10 to 20 years are simply not anticipated.

Current curricula are overloaded and do not easily offer opportunities to include novel knowledge. As well, teaching goals and learning objectives are fixed for apparent long-term stability of professional practices. Evaluation of the candidates' competencies is derived from such expectations and established

\author{
Helena Jenzer \\ Bern University of Applied Sciences \\ and Psychiatric University Clinic Zürich, \\ Switzerland
}

\section{Corresponding author: Helena Jenzer}

\section{helena.jenzer@bluewin.ch}

Bern University of Applied Sciences and Psychiatric University Clinic Zürich, Switzerland.

Tel: +41794019235

Citation: Jenzer H. Missing to Meet Dieticians and Nutritionists' Educational Needs is Not Only a Question of Governmental Austerity Measures. J Clin Nutr Diet. 2017, 3:1.

practices. It is still in the responsibility of those teachers who often emerged themselves out of a non-academic curriculum and do not have insight in related (natural) sciences. This means in terms of clinical nutrition and dietetics, that numbers of candidates beginning their studies in nutrition and dietetics never had a sufficient natural scientific education. The absence of knowledge in chemistry, biochemistry, physics, and biology leads to black boxes of mechanistic knowledge which never will be filled. In the past, treatments favoured by overridden nutritional concepts have led to disastrous long-term outcomes of nutritional therapies. Typical non-communicable diseases induced or at least favoured by erroneous nutritional behaviour still proceed and reach pandemic dimensions. There is not basically a lack in clinical trials, but a lack in the knowledge of biochemically precise pathways. The world does not need more reports on guidelines issued from local expert groups evaluating regionally restricted settings. The world would profit from more elucidation of biochemical mechanisms. A typical example would be the added value of glutamine in clinical nutrition. As the biochemical pathway of glutamine biosynthesis depends on an energy-dependent step, only those studies make sense which have been examining patients in a catabolic state and suffering from energy protein malnutrition. This is simply forgotten due to the unwise chase for evidence. True scientist knows that absence of evidence is not equal to evidence of the absence of an effect. 
In contrast to medical professions, some health professions have become academic in the past few years only. The step to academic behaviour and level however is not yet entirely performed. Research is not truly welcome in this setting. A student talented for research and innovation is in such a system neither recognised nor supported by research-unfriendly teachers, as they feel perfectly well in their current professional situations. Thus, the teacher's problem becomes the student's problem. Instead of fostering those students who bring with them talent, motivation, and basic knowledge, access to tertiary education proposed by the Bologna philosophy is open for undergraduate or lateral entrants from preparatory schools with no or less requiring access tests. This prevents the approximation of recent academic health professions to traditional academic medical professions. Once legitimately admitted to practise, these emerging academic disciplines are not yet required to attend continuing educational activities and to proof life-long learning activities by a credit system. There is a major risk that without requested proofs of continuing education a low level scientific knowledge remains throughout a professional career. It is even worse if representatives of such a profession become part of an incestuous system which aims to just prevent a status quo. As in nature, where recombined genetic codes make evolution precede steadily, science needs grade and skill mix with knowledge from other professions working with other methodologies. More interdisciplinarity among faculty members is needed to override these educational pitfalls. As long as teachers themselves are afraid of these challenges, curricula will not be improved to a quality or to a quantity which enables keeping up with the scientific requirements. 


\section{References}

1 Sadeghi L, Martins S, Müller S, Ruch L, Jenzer H (2017) Continuing Educational Needs and Preferences for Swiss Registered Dietitians: Lessons Learned. J Clin Nutr Diet 3: 3. 